\title{
IBM PELATIHAN CMS CONTENT DAN DIGITAL JURNALISTIK
}

\author{
Nurliana Nasution*1, Mhd Arief Hasan ${ }^{2}$ \\ 1,2Program Studi Teknik Informatika, Fakultas Ilmu Komputer, Universitas Lancang Kuning \\ *E-mail: nurliananst@ unilak.ac.id
}

\begin{abstract}
The rapid advancement of information technology and its widespread utilization potential, opens opportunities for accessing, managing, and utilizing large volumes of information quickly and accurately. The fact has shown that the use of internet media is a very important factor. Submission of information through the website is common and is an effective medium for publishing news to the general public. Pondok Pesantren Mahasiswa Miftahul Huda Panam Pekanbaru. Is a Pondok Pesantren established to foster student students who are smart, faqih and pious. Pondok pesantren is under the foundation miftahul huda shade of Islamic Da'wah Institutions Indonesia Riau Province. DPW LDII Riau Province already has a website that can be accessed by the whole community. But the existence of the current website is still practically fakum. Alias Dead Suri due to lack of human resources are active in filling the website content. After a discussion with a team of devotion, it was agreed that this issue was promoted to a Community Service program. In the course of IBM later students are not only taught about content CMS website DPW LDII Riau but will also be taught about the basics of journalism. In order for students at Pondok Pesantren Miftahul Huda Panam to understand how to create a good news article and fill it in the website DPW LDII RIAU.
\end{abstract}

Keywords-CMS, Journalism, Training, Website

\begin{abstract}
Abstrak
Kemajuan teknologi informasi yang demikian pesat serta potensi pemanfaatannya secara luas, membuka peluang bagi pengaksesan, pengelolaan, dan pendayagunaan informasi dalam volume yang besar secara cepat dan akurat. Kenyataan telah menunjukkan bahwa penggunaan media internet merupakan faktor yang sangat penting. Penyampaian informasi melalui website sudah umum dan merupakan media efektif untuk mempublikasi berita ke khalayak umum. Pondok Pesantren Mahasiswa Miftahul Huda Panam Pekanbaru. Merupakan Pondok Pesantren yang didirikan untuk membina insan mahasiswa yang cerdas, faqih dan alim. Pondok pesantren ini berada di bawah yayasan miftahul huda naungan Lembaga Dakwah Islam Indonesia Provinsi Riau. DPW LDII Provinsi Riau sudah memiliki website yang dapat diakses oleh seluruh masyarakat. Namun keberadaan website saat sekarang ini masih dibilang fakum. Alias Mati suri dikarenakan kurangnya sumberdaya manusia yang aktif dalam mengisi konten website tersebut. Setelah diadakan diskusi dengan tim pengabdian maka disepakatilah permasalahan ini diangkat menjadi program Pengabdian Masyarakat. Dalam kegiatan IBM nanti mahasiswa tidak hanya diajarkan mengenai pengisian konten website CMS DPW LDII Riau namun juga akan diajarkan tentang dasar-dasar jurnalistik. Agar mahasiswa di Pondok Pesantren Miftahul Huda Panam memahami bagaimana cara membuat sebuah artikel berita yang baik dan mengisinya di dalam website DPW LDII RIAU.
\end{abstract}

Kata kunci-CMS, Jurnalistik, Pelatihan, Website

\section{PENDAHULUAN}

Kemajuan teknologi informasi yang demikian pesat serta potensi pemanfaatannya secara luas, membuka peluang bagi pengaksesan, pengelolaan, dan pendayagunaan informasi dalam volume yang besar secara cepat dan akurat. Kenyataan telah menunjukkan bahwa penggunaan media internet merupakan faktor yang sangat penting. Penyampaian informasi melalui website sudah umum dan merupakan media efektif untuk mempublikasi berita ke khalayak umum. 
Content Management System adalah perangkat lunakyang digunakan untuk menambahkan atau memanipulasi (mengubah) isi dari suatu situs web. Umumnya, sebuah CMS (Content Management System) terdiri dari dua elemen: aplikasi manajemen isi (Content Management Application, CMA). aplikasi pengiriman isi (content delivery application, CDA) Elemen CMA digunakan untuk mengelola konten yang mungkin tidak memiliki pengetahuan mengenai HTML untuk mengelola pembuatan, pengubahan, dan penghapusan isi dari suatu situs web tanpa perlu memiliki keahlian sebagai seorang webmaster. Elemen CDA menggunakan dan menghimpun informasi-informasi yang sebelumnya telah ditambah, dikurangi atau diubah oleh pemilik situs web untuk memperbaharui situs web tersebut. Kemampuan atau fitur dari sebuah sistem CMS berbeda-beda. Walaupun begitu, kebanyakan dari perangkat lunak ini memiliki fitur publikasi berbasis Web, manajemen format, kontrol revisi, pembuatan indeks, pencarian, dan pengarsipan (Wikipedia).Dalam pelaksanaannya Content Management system sudah menjadi kebutuhan dasar dalam pembuatan website.

Pondok Pesantren Mahasiswa Miftahul Huda Panam Pekanbaru. Merupakan Pondok Pesantren yang didirikan untuk membina insan mahasiswa yang cerdas, faqih dan alim. Pondok pesantren ini berada di bawah yayasan miftahul huda naungan Lembaga Dakwah Islam Indonesia Provinsi Riau. Dalam pelaksanaannya di Pondok Pesantren ini terdiri dari mahasiswa-mahasiswa yang berkuliah di Perguruan Tinggi di Seluruh Kota Pekanbaru. Pondok pesantren ini sekaligus menjadi asrama bagi mahasiwa dalam membina keilmuan agama. Dalam kegiatan hariannya mahasiswa di tempat ini kuliah di kampus mereka masing-masing. Kemudian di waktu Pagi, Sore dan malam diisi dengan kegiatan keilmuan agama. Target akhir dari pondok pesantren ini adalah menciptakan sarjana yang faqih, alim dan berakhlakul karimah.

Disamping itu dalam kegiatan hariannya mahasiswa yang berada di bawah Pondok Pesantren Mahasiswa Miftahul Huda Panam ini juga aktif dalam setiap kegiatan yang di adakan oleh Lembaga Dakwah Islam Indonesia Provinsi Riau. Mereka rutin membantu dalam setiap urusan berkaitan dengan Organisasi DPW LDII Provinsi Riau. DPW LDII Provinsi Riau sudah memiliki website yang dapat diakses oleh seluruh masyarakat. Namun keberadaan website saat sekarang ini masih dibilang fakum. Alias Mati suri dikarenakan kurangnya sumberdaya manusia yang aktif dalam mengisi konten website tersebut.

Disamping itu Pengurus DPW LDII Riau berharap akan adanya Pondok Pesantren Mahasiswa ini bisa membantu mengisi konten yang ada. Namun karena keterbatasan pengetahuan yang dimiliki maka perlunya diadakan pelatihan kader dalam pengisian konten website DPW LDII Riau ini. Setelah diadakan diskusi dengan tim pengabdian maka disepakatilah permasalahan ini diangkat menjadi program Pengabdian Masyarakat. Dalam kegiatan IBM nanti mahasiswa tidak hanya diajarkan mengenai pengisian konten website CMS DPW LDII Riau namun juga akan diajarkan tentang dasar-dasar jurnalistik. Agar mahasiswa di Pondok Pesantren Miftahul Huda Panam memahami bagaimana cara membuat sebuah artikel berita yang baik dan mengisinya di dalam website DPW LDII RIAU.

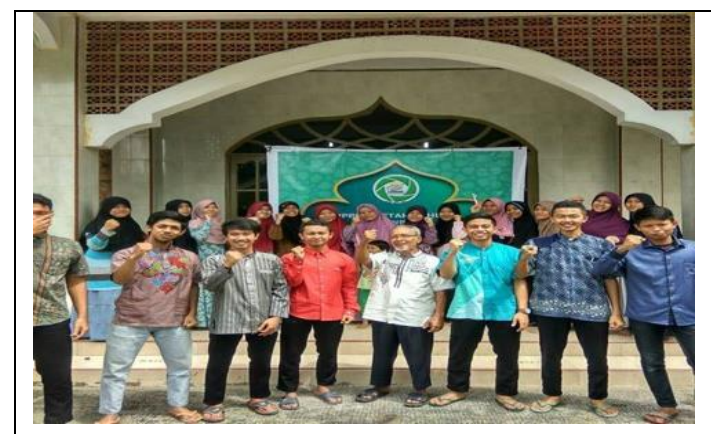

Gambar 1 Mahasiswa Pondok Pesantren Mahasiswa Miftahul Huda

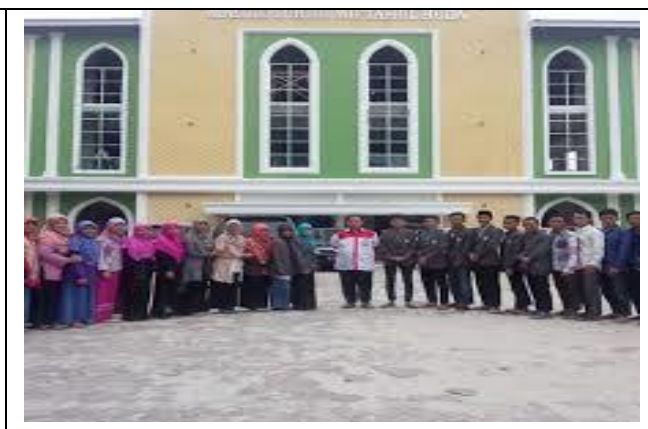

Gambar 2 Bersama Pengurus 


\section{METODE}

Metode pelaksanaan kegiatan IBM ini dilakukan di Pondok Pesantrean Miftahul Huda Kelurahan Tangkerang Utara Kota Pekanbaru dengan diagram dibawah ini.

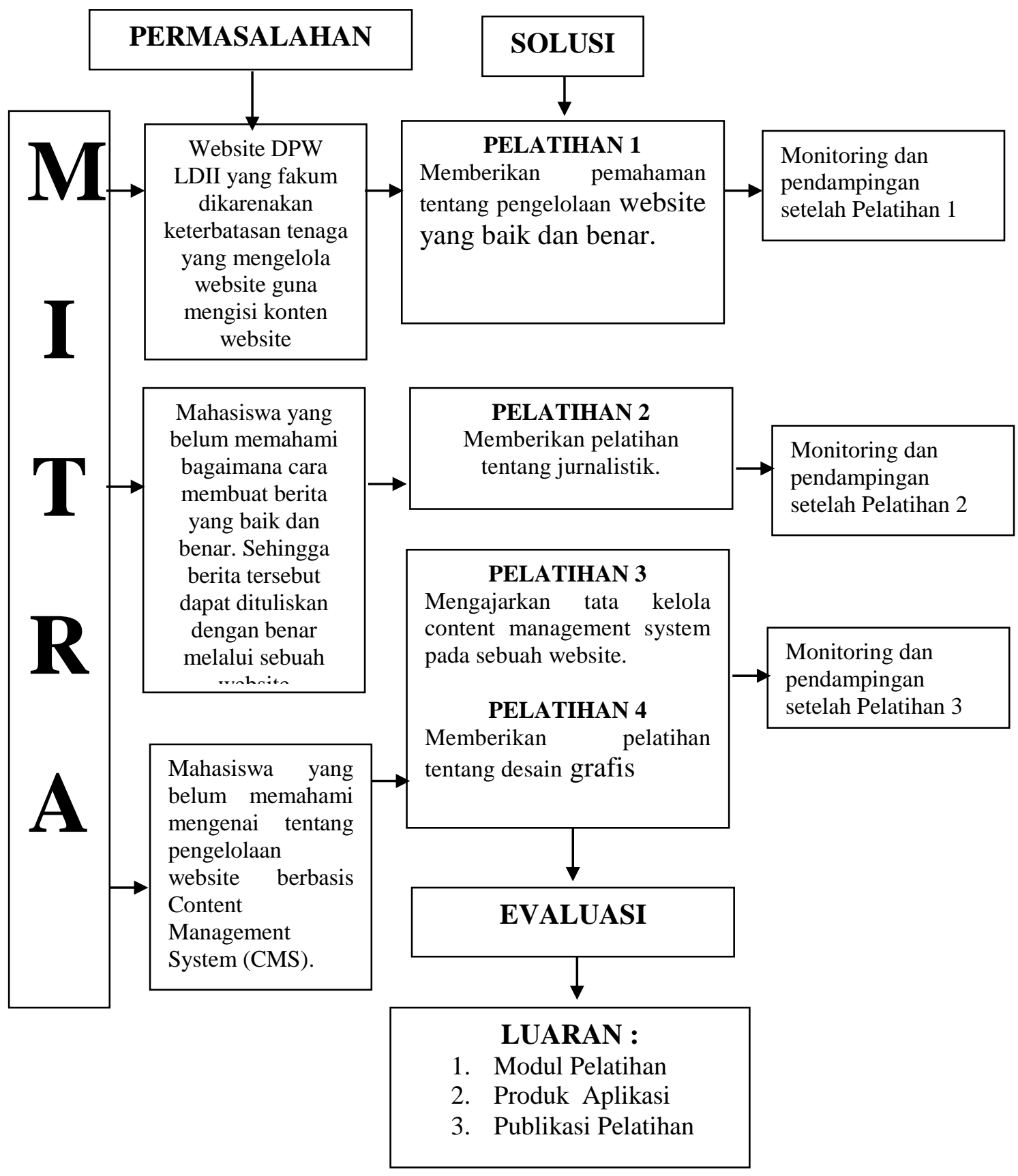

Gambar 3 Metode Pelaksanaan

\section{HASIL DAN PEMBAHASAN}

\subsection{Road Map Pengabdian}

Pengabdian ini merupakan pengabdian sesi/tahap ke tiga (3) yang telah dilakukan para narasumber/dosen bersama tim di Pondok Pesantren Mahasiswa Miftahul Huda, fokus penganbdian yang dilakukan adalah tentang naskah pembuatan berita bagi para mahasiswa 
yang ditunjuk olek Pengurus DPW LDII Provinsi Riau yang akan bertindak sebagai administrator website.

Berikut merupakan tabel roadmap kerja yang telah dilakukan oleh para narasumber (dosen ) bersama tim yang telah dilakukukan:

\begin{tabular}{|c|c|c|c|}
\hline No & $\begin{array}{l}\text { Waktu } \\
\text { Kegiatan }\end{array}$ & Uraian Kegiatan & Hasil \\
\hline 1. & Februari 2018 & $\begin{array}{l}\text { Sosialasi di Organisasi Adijaya, } \\
\text { tentang pentingnya internet. }\end{array}$ & $\begin{array}{l}\text { Disetujuinya } \\
\text { rancangan } \\
\text { pembuatan website } \\
\text { LDII RIAU }\end{array}$ \\
\hline 2. & Maret 2018 & $\begin{array}{l}\text { Tindak lanjut dalam pembuatan } \\
\text { website organisasi }\end{array}$ & $\begin{array}{l}\text { Terwujudnya website } \\
\text { LDII RIAU, dengan } \\
\text { alamat/link: www. } \\
\text { ldiiriau.or.id }\end{array}$ \\
\hline 3. & $\begin{array}{l}\text { April - Mei } \\
2018\end{array}$ & $\begin{array}{l}\text { Pelatihan/pemberian ketrampilan } \\
\text { bagi para mahasiswa tentang } \\
\text { pembuatan serta etika } \\
\text { penguploadan informasi } \\
\text { website } \text { organisasi. }\end{array}$ & $\begin{array}{l}\text { Operator organisasi } \\
\text { telah } \quad \text { mampu } \\
\text { mengupload } \\
\text { informasi ke dalam } \\
\text { website organisasi. }\end{array}$ \\
\hline 4. & $\begin{array}{l}\text { Juni - Juli } 2018 \\
\text { ( dalam tahapan) }\end{array}$ & $\begin{array}{l}\text { Pelatihan/ pemberian ketrampilan } \\
\text { dalam bidang fotografi untuk } \\
\text { menambah kelengkapan dalam } \\
\text { website organisasi }\end{array}$ & \\
\hline
\end{tabular}

\subsection{Materi Pengabdian Tahap 3}

Tidak ada teori atau teknik khusus yang bisa membuat seseorang mahir dalam menulis berita. Kemahiran dalam menulis berita, bisa dimiliki dengan latihan dan kebiasaan. Selain itu, kemahiran menulis itu juga bisa didapatkan jika kita rajin membaca buku, majalah, surat kabar dan meyimak berita di televisia atau radio. Menurut Setiati (2005), sebelum menulis berita, berita mana yang layak untuk di tulis. Untuk itu bisa menggunakan rumus KISS ( keep it Simple and Short). Gunakan istilah atau ungkapan yang sering dipakai. Tulisan yang akan dibuat hendaknya dapat memancing rasa ingin tahu pembaca.

Untuk bisa menulis berita dengan baik Setiati (2005) dapat mempehatikan pedoman sebagai berikut:

a. Communicative

Kenalilah semua peristiwa yang akan Anda liput.Dengan demikian, Anda bisa menulis berita dengan baik berdasarkan laporan pengumpulan data dan wawancara.

b. Communicative is the Goal

Ketika menulis berita, usahakanlah melakukan komunikasi denagn menggunakan bahasa tulisan untuk menyampaikan ide, pemikiran,informasi kepada pembaca.

c. Clarity is the Keynote of Good Writing

Tulislah liputan yang telah Anda kumpulkan itu berdasarkan fakta dan data. Dalam penulisan berita, kejelasan fakta merupakan kunci penulisan berita yang baik. Agar pembaca dapat memahami isi tulisan anda, gunakan bahasa yang mudah dipahami, sederhana, tidak bertele-tele, kalimat pendek, dan hindari penggunaan anak kalimat. Supaya penulisan berita Anda mengalir, buatlah kerangka penulisan yang didasarkan pada kerangka wawancara.

d. Writing is a Process

Menulis itu membutuhkan keahlian khusus, apalagi dalam menulis berita. Dibutuhkan keahlian khusus (writing technique), latihan, kejelian, dalam menganalisa peristiwa, 
wawasan, dan kesabaran, untuk terus mencoba menulis berita menarik perhatian anda. Untuk bisa menulis berita yang baik, Anda perlu berlatih dan rajin menganalisa berita-berita yang dimuat di media massa. Pelajarilah gaya penulisan wartawan senior agar Anda dapat mengenali alur penulisan berita yang didasarkan pada teknik piramida terbalik, yaitu tulis berita yang paling penting, penting, kurang penting, dan tidak penting, uang dapat Anda gambarkan susunannya sebagai piramada terbalik

Dalam pengabdian dalam tiga (3) ini, ada beberapa materi yang disampaikan, khususnya dalam penulisan naskah berita. Shahab (2008) menjelaskan ada beberapa aturan yang harus diperhatikan dalam pembuatan sebuah berita, yaitu:

\section{a. Struktur Berita}

Dalam penulisan berita, ada kerangka sebagai pegangan yang memudahkan seorang jurnalis untuk menulis sebuah berita. Dalam kerangka teori jurnalistik, kerangkapenulisan berita in lazinm disebut sebagai Piramida Terbalik. Model ini menurut Shahab, memiliki tiga tujuan, yaitu:

- Untuk menarik perhatian pembaca

- Memudahkan bagi pembaca mengetahui isi berita

- Tidak mengurangi isi berita bila terjadi pemotongan karena kolm (space) yang tersedia tidak cukup membuat keseluruhan berita.

\section{Judul Berita}

Judul berita untuk surat kabar biasanya disebut sebagai Headline. Sedangkan untuk majalah atau penerbitan berkala disebut titles atau heading.Ada dua pengertian tentang headline dalam arti judul berita. pengertian headline kedua adalah berita utama.

Dalam pembuatan judul berita, ada tiga hal yang patut diperhatikan dalam membuat judul berita. Pertama, Judul berita harus merupakan intisari atau perasaan dari teras berita. Kedua, judul berita harus mengandung isi yang positif. Ketigam Judul berita sebaiknya menggunakan kalimat lengkap.

\section{Dateline}

Penulisan dateline atau tempat dan waktu terjadinya suatu peristiwa, yang pertama adalah berkaitan dengan kota atau tempat terjadinya peristiwa atau pendapat. Yang Kedua merupakan keterangan waktu kapan peristiwa atau pendapat tersebut terjadi. Teras berita Bagian terpenting dari sebuah struktur berita adalah teras berita atau lead. Oleh karena itu, teknik penulisan teras berita harus dikuasi seorang jurnalis. Pada seorang jurnalis pemula, kerap mengeluh, " dari mana saya harus mulai menulis?"

\section{b. Nilai Berita}

Nilai berita (news values), menurut Downie JR dan Kaiser ( dalam Santana, 2005), merupakan istilah yang tidak mudah didefiniskan. Istilah ini meliputi segala sesuatu yang tidak mudah dikonsepsikan. Ketinggian nilainya tidak mudah untuk dikonkretkan. Dalam penulisan berita, ada beberapa elemen berita yang harus diingat. Beberapa elemen nilai berita, yang mendasari pelaporan berita yaitu:

a. Immediacy.

Immediacy biasa diistilahlkan dengan timelines. Artinya dengan kesegaran peristiwa yang dilaporkan. Sebuah berita sering dinyatakan sebagai laporan dari apa yang baru saja terjadi.

b. Proximity adalah keterdekatan peristiwa dengan pembaca atau pemirsa dalam keseharian hidup mereka. Misalny, stasiun, terminalm klub, kota)

c. Consequence adalah berita yang mengubah kehidupan pembaca adalah berita yang mengandung nilai konsekuensi. Misalnya, kenaikan harga BBM, putusan perlemen.

d. Conflic adalah peristiwa perang, demonstrasi atau kriminal merupakan contoh elemen konflik di dalam pemberitaan. 
e. Oddity adalag peristiwa yang tidak biasa terjadi. Adalah sesuatu yang akan diperlihatkan segera oleh masyarakat. Misalnya bayi kembar lima. Atau gempa yang berkekuatan tinggi.

f. Sex.Sex kerap menjadi satu elemen utama dari sebuah pemberitaan. Tapi sex kerap menjadi elemenen tambahan bagi pemberitaan.

g. Emotion (human Interest) Elemen ini mentangkut kisah-kisah yang mengandung kesedihan, kemarahan, simpati atau ambisa ( Komedi/ tragedi)

h. Prominence (names make news) atau nama membuat berita. Ketika seseorang menjadi terkenal maka ia akan selalu diburu oleh pembuat berita.

i. Suspense menunjukkan sesuatu yang ditunggu-tunggu, terhadap sebuah peristiwa. Misalnya ketegangan menunggu pecahnya peran IRAK.

j. Progress merupakan elemen 'perkembangan' periswtiwa yang ditunggu masyarakat.

\subsection{Hasil Pengabdian}

Gambar 3 tersebut merupakan, hasil dari pengabdian yang telah dilakukan. Organisasi Adijaya telah memiliki website Organisasi, dengan alamat www. ldiiriau.Or.id.

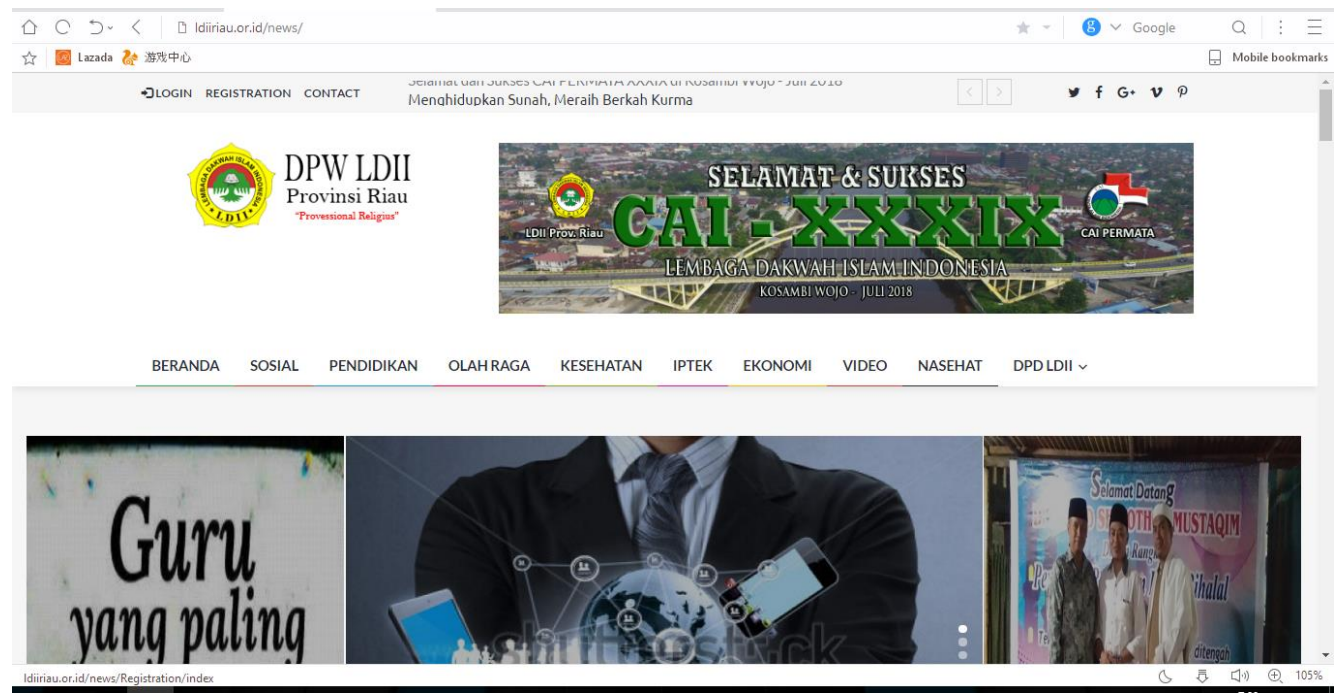

Gambar 4 Tampilan Beranda Website Organisasi

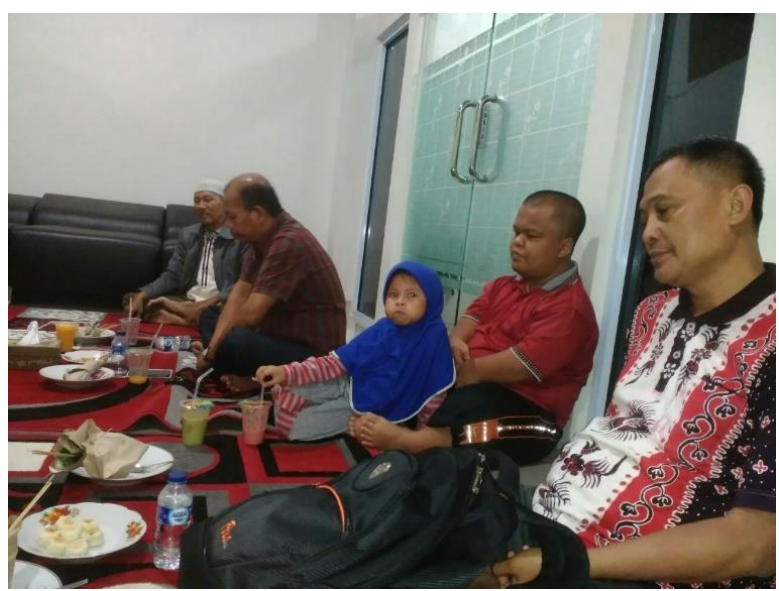

Gambar 5 Launching Website Oleh Pimpinan Organisasi

Pada pengabdian tahap 3, ini dilakukan dengan pemberian ketrampilan dalam pembuatan naskah berita yang akan di upload dalam website DPW LDII RIAU. Pembuatan naskah berita dilakukan telah sesuai dengan etika jurnalistik yang ada. 


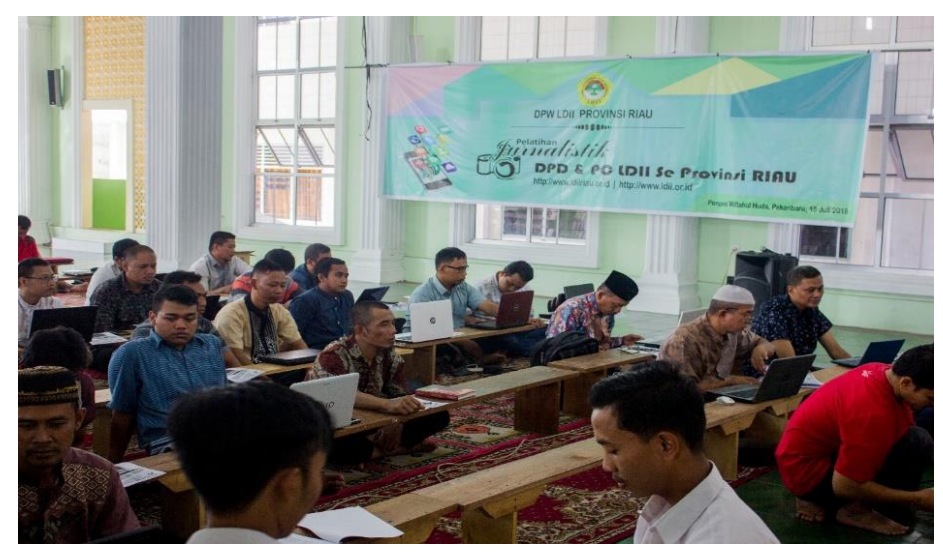

Gambar 5 Pelatihan Pembuatan Naskah Berita di DPD LDII RIAU Mahasiswa Bersama Perwakilan DPD LDII Se- Riau

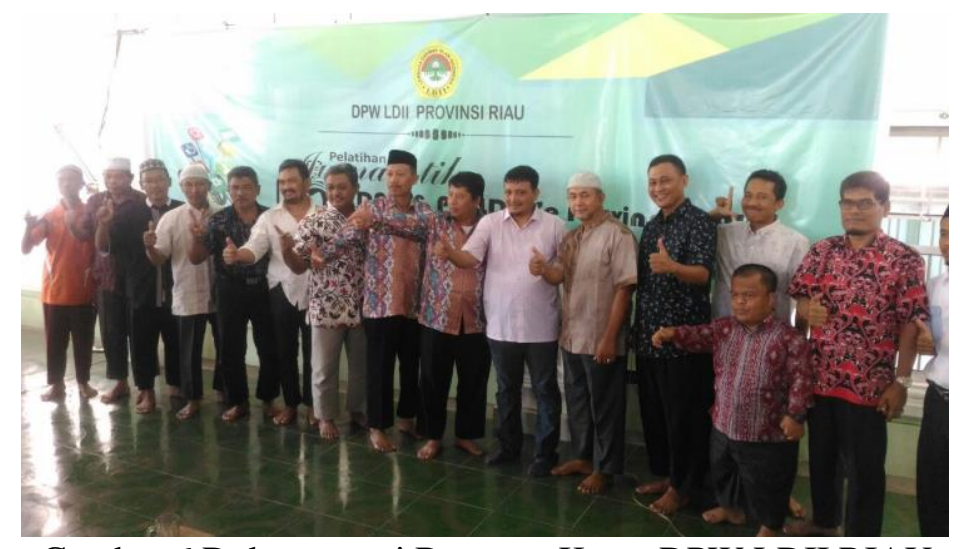

Gambar 6 Dokumentasi Bersama Ketua DPW LDII RIAU

Setelah diadakan sosialisasi Tim Pengabdian Masyarakat melakukan evaluasi Pasca Pelatihan. Dari hasil sosialisasi tersebut dihasilkan grafik sebagai berikut.

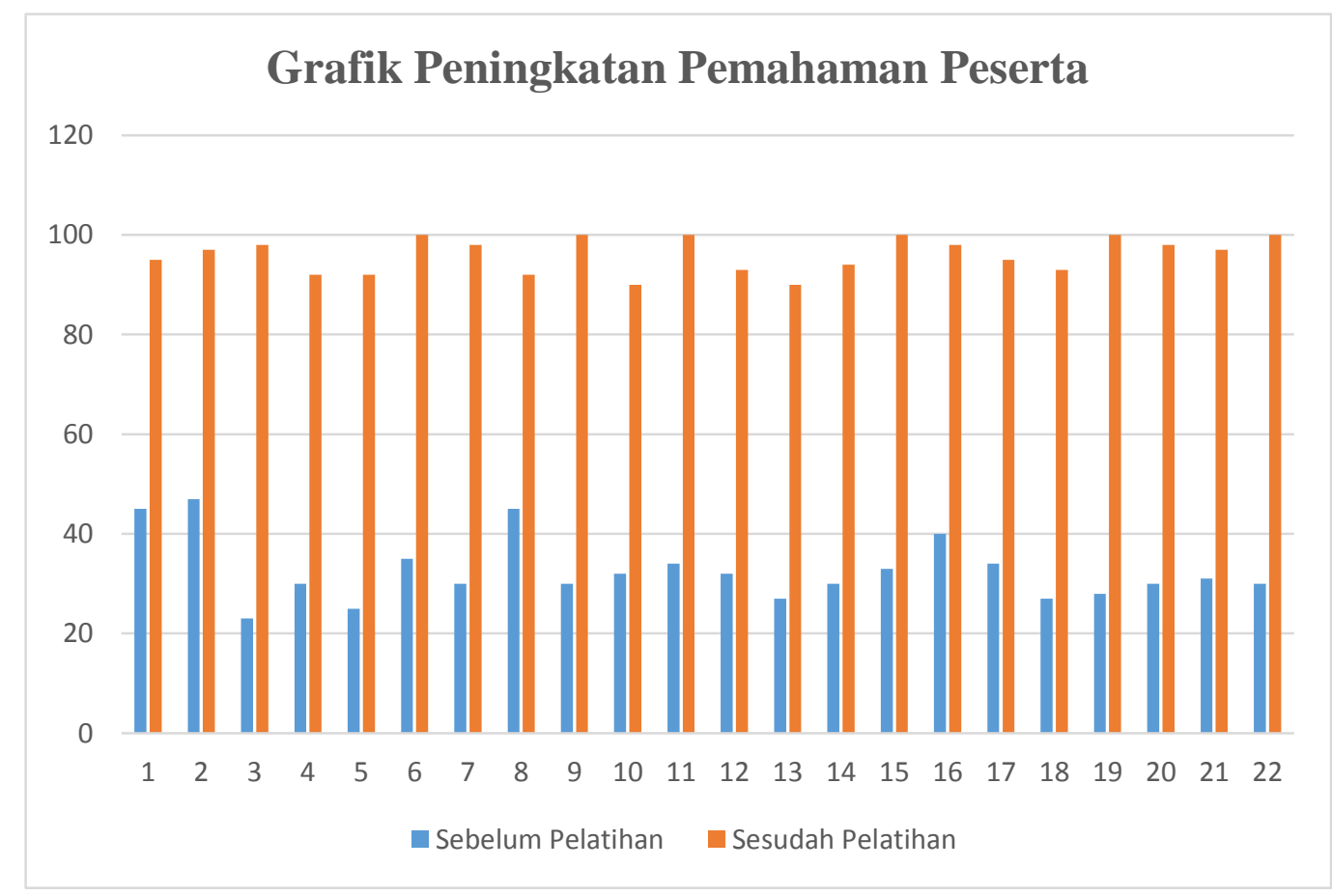

Gambar 7 Grafik Pemahaman Peserta 


\subsection{Pendampingan Pasca Pengabdian}

Setelah diadakannya pelatihan tentu peserta akan mengalami banyak kendala setelah pelaksanaan. Oleh karenanya tim pengabdian membuat komunitas Grup Whatsappp untuk mengantisipasi kendala yang dialami peserta pasca pelatihan.

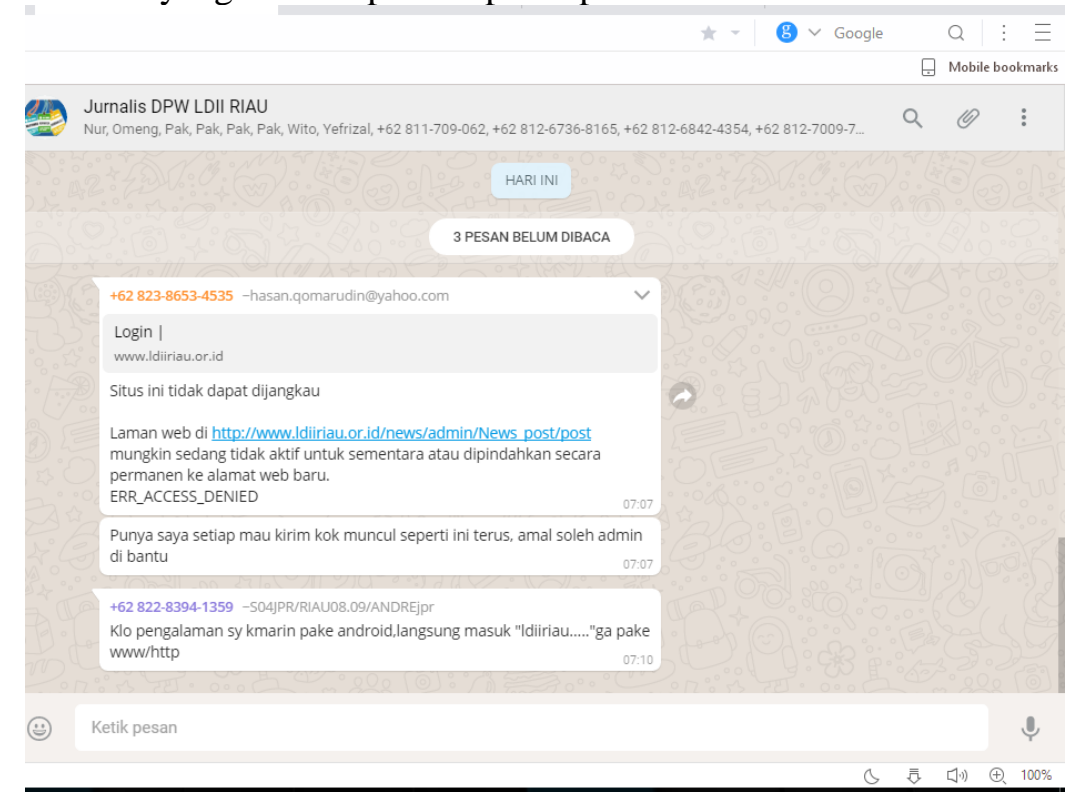

Gambar $8:$ Komunitas Whatsapp

\section{KESIMPULAN}

Berdasarkan pelaksanaan pengabdian yang telah dilakukan, terdapat beberapa kesimpulan yang diperoleh yaitu:

a. Organisasi LDII telah 'bermigrasi' sebagai Organisasi global village dengan mamnfaatkan internet sebagai langkah awal dalam memberikan informasi kepada masyarakat dengan memiliki website ldiiriau.or.id.

b. Aparatur DPW LDII RIAU, telah memiliki kemampuan ketrampilan dalam mengoperasionalkan website Organisasi dengan langsung menjadi administrator website.

c. Aparatur DPW LDII RIAU, telah memiliki kemampuan dalam pembuatan naskah berita ataupun informasi yang akan dipublish ke website Organisasi.

\section{SARAN}

a. Pelaksanaan pengabdian dengan fokus pembuatan website di DPW LDII RIAU, perlu dilanjutkan kepada desa-desa atau Organisasi-Organisasi yang lain untuk mengembangkan potensi Organisasi yang ada.

b. Pendampingan kepada Organisasi harus terus dilakukan secara berkelajutan terutama pada pemberian ketrampilan pembuatan naskah berita/informasi di website Organisasi.

\section{UCAPAN TERIMA KASIH}

Penulis mengucapkan terima kasih kepada Lembaga Penelitian dan Pengabdian Masyarakat Universitas Lancang Kuning yang telah membantu dalam pelaksanaan program pengabdian masyarakat ini. Dan terimakasih kepada Pihak DPW LDII Riau yang sudah membantu amalsoleh pelaksanaan kegiatan ini, 


\section{DAFTAR PUSTAKA}

[1] Hogan, B.P. 2013. HTML5 and CSS3: Level Up with Today's Web Technologies, Second Editon. Dallas, TX, USA: PragmaticProgrammers.

[2] Clark, R., Studholme, O., Murphy, C., \& Manian, D. 2012. Beginning HTML5 and CSS 3. New York, NY, USA: Apress.

[3] David, M. 2010. HTML5 Designing Rich Internet Application. Burlington, MA, USA: Elsevier.

[4] Devlin, I. 2012. HTML5 Multimedia: Develop and Design. Berkeley, CA, USA: Peachpit.

[5] Gilmore, W.J. 2011. Easy PHP Websites with the Zend Framework. USA: WJ Gilmore.

[6] Goldstein, A., Lazaris, L., \& Weyl, E. 2011. HTML5 \& CSS3 for the Real World. Collingwood, VIC, Australia: SitePoint.

[7] Gustafson, J.M. 2013. HTML5 Web Application Development By Example: Beginner's guide.Birmingham, UK: Packt.

[8] Powell, T.A. 2010. HTML \& CSS: The Complete Reference, Fifth Edition. New York, NY,USA: McGraw-Hill.

[9] Robbins, J.N. 2013. HTML5 Pocket Reference, Fifth Edition. Sebastopol, CA, USA: O'Reilly.

[10] Sanders, B. 2011. Smashing HTML5, FirstEdition. Chichester, West Sussex, UK: John Wiley $\&$ Sons. 